\title{
ASPECTOS GERAIS ACERCA DA POLUIÇÃO SONORA
}

\section{Davi Cruz Fernandes ${ }^{1}$}

RESUMO: O presente trabalho aborda os aspectos norteadores que envolvem a poluição sonora, tais quais seus danos à saúde em seres humanos, seus limites legais, suas fontes de ruído, a competência para legislar no caso concreto e os aspectos penais envolvidos e abordados nas leis de crimes ambientais e de contravenções penais.

Palavras-chave: Poluição sonora, fontes de ruído, crimes ambientais.

\section{INTRODUÇÃO}

Nos dias de hoje, tem-se percebido que os grandes centros urbanos trazem consigo muitos problemas relacionados a grandes áreas norteadas por indústria, comercio e um grande contingente populacional. Um desses problemas é a Poluição Sonora, presente no dia a dia da população urbana e uma questão já considerada de saúde pública.

A Poluição Sonora é complexa, pois atinge a coletividade e produzida por diversas fontes, as quais em muitas ocasiões fazem parte até mesmo da cultura local ou é causada de forma eventual porém não mesmo degradante.

O bem-estar de todos assim como um meio ambiente ecologicamente equilibrado, nos remete a um tratamento complexo no que diz respeito ao

\footnotetext{
${ }^{1}$ Bacharel em Engenharia de Comunicações, Agente de Proteção Ambiental - Secretaria Municipal de Meio Ambiente e Sustentabilidade - Prefeitura de Manaus. dcfmetal@gmail.com
} 
combate a poluição sonora, que assim como qualquer outra forma de poluição, exige políticas públicas e um estudo preciso de como evitar tal desconforto.

\title{
ASPECTOS ACERCA DA POLUIÇÃO SONORA
}

Quando abordamos o tema Poluição Sonora, a primeira consideração a ser feita é a respeito da diferença entre um som, de qualidade agradável, para os que apreciam uma boa sonoridade, e o ruído, causador de desconforto e de danos à saúde.

De acordo com FIORILLO (2011) é possível afirmar:

\begin{abstract}
Som é qualquer variação de pressão (no ar, na água...) que o ouvido humano possa captar, enquanto ruído é o som ou conjunto de sons indesejáveis, degradáveis, perturbadores. $\mathrm{O}$ critério de distinção é o agente perturbador, que pode ser variável, envolvendo o fator psicológico de tolerância de cada indivíduo.
\end{abstract}

Os ruídos também possuem tipos distintos, como por exemplo, o os contínuos e descontínuos, onde estes podem causar um desconforto bem maior pelo fato de serem ruídos do tipo impulsivo, seus níveis capazes de causar desconforto são menores do que os se apresentam em ruído do tipo contínuo.

Com uma natureza de agente poluidor, o ruído difere evidentemente de outros agentes poluidores, como os da água, do ar, do solo, principalmente no que diz respeito a sua nocividade com relação aos seres humanos, os mais afetados com a contaminação.

Os efeitos do ruído nos seres humanos, principalmente os que residem em grandes centros urbanos, já são notoriamente uma questão de saúde pública. De acordo com o que discorre SOUZA: 


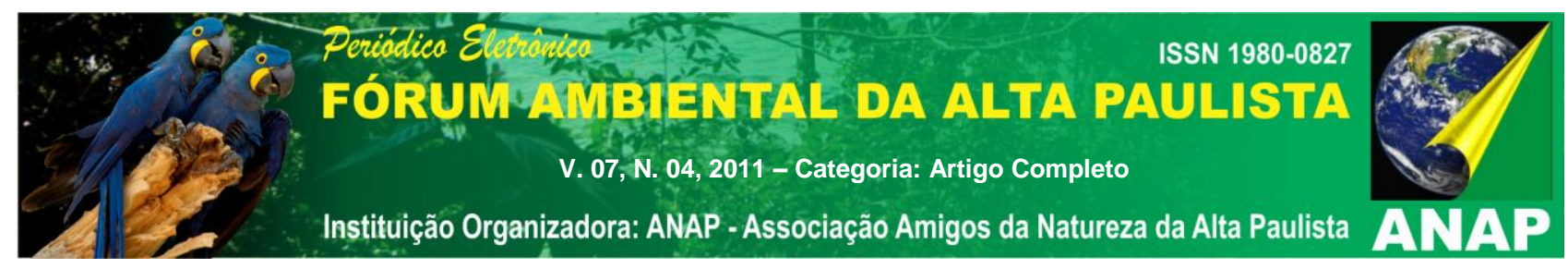

Acrescente-se que a poluição sonora e o estresse auditivo são a terceira causa de maior incidência de doenças do trabalho. Além disso, verifica-se que o ruído estressante libera substâncias excitantes no cérebro, tornando as pessoas sem motivação própria, incapazes de suportar o silêncio.

Sintomas como a perda auditiva, estresse, são apenas uma pequena parte dos efeitos reais que pode causar a exposição a ruídos nos seres humanos, assim como nos relata KWITKO (1993):

\begin{abstract}
O indivíduo exposto ao ruído pode apresentar alguns sintomas não auditivos como:nervosismo, fadiga física e mental, dificuldade no relacionamento social, insônia, tortura, irritabilidade, aumento na freqüência cardíaca e respiratória, aumento na pressão arterial, dilatação pupilar, contração muscular, perda de concentração, distúrbio de visão, alterações gastrointestinais etc.

Além disso, existem os efeitos específicos do ruído ao sistema extraauditivo: fadiga muscular; alterações no sistema cardiovascular, ocasionando um aumento dos batimentos cardíacos e, com isso o aumento do risco coronariano; alterações no sistema pulmonar com aumento do ritmo respiratório com hiperventilação; alterações no sistema metabólico e endócrino, com alterações no sangue e na urina e, aumento na produção de adrenalina; alterações no Sistema Nervoso Central ocasionando problemas visuais e vertigem do tipo rotatória; alterações no sistema gastrointestinal como náuseas, epigastralgia e até hemorragias.
\end{abstract}

Observe-se que não há tratamento para lesões auditivas decorrentes de trauma sonoro ou acústico, a não ser o afastamento definitivo do indivíduo do ambiente.

Os ruídos causadores de danos aos seres humanos advêm de diversas fontes poluidoras, tais quais possuem características peculiares e relacionadas com suas respectivas realidades locais. As fontes legais de poluição sonora, consideradas assim como atividades poluidoras, são entre outras:

- Cultos religiosos;

- Bares e casas noturnas;

- Aeroportos;

- Indústrias;

- Veículos Automotores. 
and $x^{2}$

. 07, N. 04, 2011 - Categoria: Artigo Completo

Instituição Organizadora: ANAP - Associação Amigos da Natureza da Alta Paulista

A identificação entre som e ruído é feita através da utilização de unidades de medição do nível de ruído. Com isso definem-se, também, os padrões de emissão aceitáveis e inaceitáveis, criando-se e permitindo-se a verificação do ponto limítrofe com o ruído. O nível de intensidade sonora (que corresponde à energia transmitida pelas vibrações) expressa-se habitualmente em decibéis $(\mathrm{dB})$.

A resolução Conama n. 1/90 regula a tutela jurídica do meio ambiente e da saúde humana, onde adota padrões estabelecidos pela Associação Brasileira de Normas Técnicas - ABNT e pela norma NBR n. 10.151, que diz respeito à avaliação do ruído em áreas habitadas, visando o conforto da comunidade.

Podemos observar na tabela 01 alguns pontos apontados pela NBR $n$ 10.151:

Tabela 01 - Nível de critério de avaliação NCA para ambientes externos, em dB(A)

\begin{tabular}{|l|c|c|}
\hline Tipos de áreas & Diurno & Noturno \\
\hline Área de sítios e fazendas & 40 & 35 \\
\hline Área estritamente residencial urbana ou de hospitais ou de & 50 & 45 \\
escolas & & \\
\hline Área mista, predominantemente residencial & 55 & 50 \\
\hline Área mista, com vocação comercial e administrativa & 60 & 55 \\
\hline Área mista, com vocação recreacional & 65 & 55 \\
\hline Área predominantemente industrial & 70 & 60 \\
\hline
\end{tabular}

Fonte: http://smmaspbh.vilabol.uol.com.br/10151.htm

Podemos afirmar que os municípios possuem a incumbência constitucional de proteger o meio ambiente, conforme podemos observar no art. 225 da Constituição Federal: 


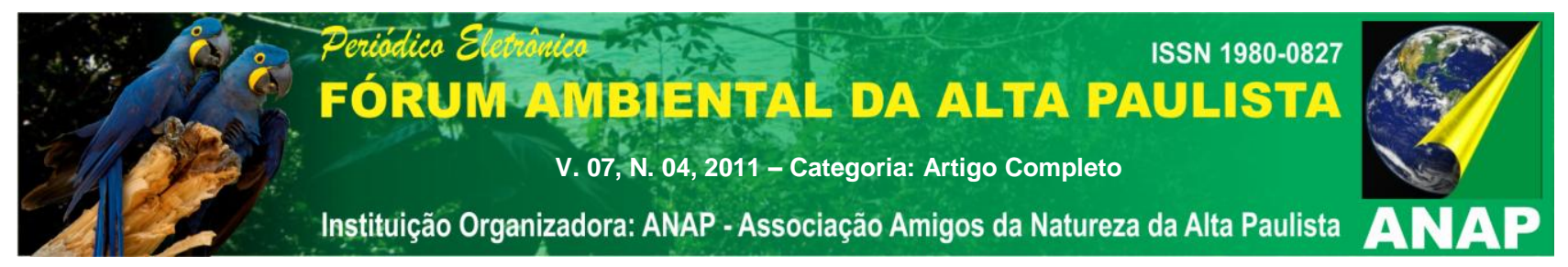

Art. 225. Todos têm o direito ao meio ambiente ecologicamente equilibrado, bem de uso comum do povo e essencial à sadia qualidade de vida, impondo-se ao Poder Público e à coletividade o dever de defendê-lo e preservá-lo para as presentes e futuras gerações.

Com relação à poluição sonora, cabe aos municípios elaborar normas de maneira supletiva e complementar relacionados com o meio ambiente, observados os estabelecidos pelo CONAMA (Conselho Nacional do Meio Ambiente), conforme se observa no art. $6^{\circ}$, $\S 2 .^{\circ}$ da Lei $6.938 / 1981$ (que dispõe sobre a Política Nacional do Meio Ambiente):

\begin{abstract}
Art. $6 .^{\circ}[\ldots]$
$\S 1 .^{\circ}$ Os Estados, na esfera de suas competências e nas áreas de sua jurisdição, elaborarão normas supletivas e complementares e padrões relacionados com o meio ambiente, observados os que forem estabelecidos pelo CONAMA.

$\S 2 .^{\circ}$ Os Municípios, observadas as normas e os padrões federais e estaduais, também poderão elaborar normas mencionadas no parágrafo anterior.
\end{abstract}

A competência dos municípios apresenta-se diante do art. 30, da nossa Lei Maior, de onde é destacado o inciso I:

Art. 30. Compete aos Municípios:

I - legislar sobre assuntos de interesse local;

Conforme destaca FURLAN e FRACALOSSI (2010):

O interesse local, verifica-se, é um conceito indeterminado, não existindo uma regra fixa para identificá-lo. Muitas vezes, apenas diante do caso concreto será possível individualizar a situação que possa ser compreendida como "interesse local" para fins de concretização de norma constitucional.

O que se percebe é que na esfera municipal que os problemas ambientais se tornam mais visíveis, reais e factíveis, de forma que os municípios podem legislar sobre meio ambiente em áreas em que pese 0 interesse local, assim exemplificado por FURLAN e FRACALOSSI (2010): 


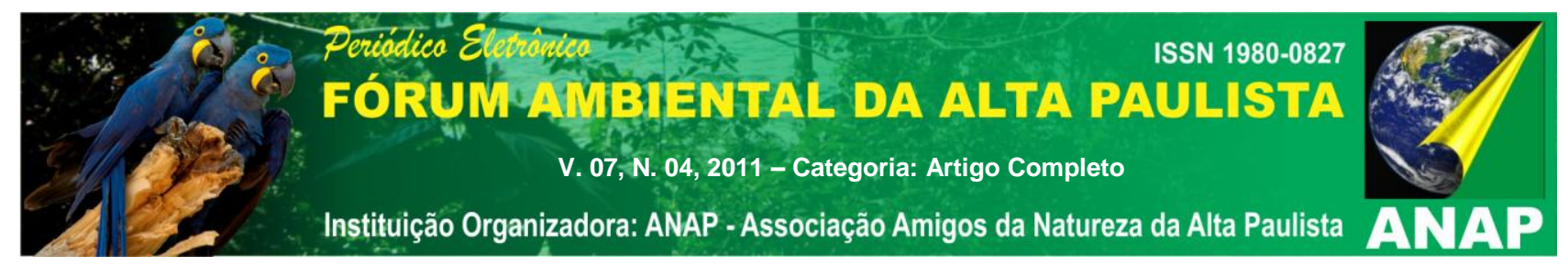

É possível destacar, dentre as áreas de interesse local as seguintes:

- espaços verdes;

- praças;

- concessão de autorizações e licenças para instalação de empreendimentos e construções;

- vias públicas;

- lixos (resíduos sólidos);

- zoneamento urbano;

- poluição sonora;

- plano diretor;

- transporte coletivo;

- parcelamento e ocupação do solo urbano;

- tombamento e patrimônio cultural;

- Código de Obras;

- Código de Saúde Municipal;

- Lei orçamentária municipal;

- Normas tributárias ambientais.

Devido a natureza do ruído ser a de agente poluidor, a poluição sonora é enquadrada como crime ambiental, descrita no art. 54 da lei n 9605/1998 Lei dos Crimes Ambientais, em sua seção de $n^{\circ} 3$ - Da poluição e outros crimes ambientais:

Art. 54 - Causar poluição de qualquer natureza em níveis tais que resultem ou possam resultar em danos à saúde humana, ou que provoquem a mortandade de animais ou a destruição significativa da flora:

Pena - reclusão, de um a quatro anos, e multa.

Uma outra abordagem relacionada ao tema em foco, é trazida na Lei das Contravenções Penais (Decreto-Lei $n^{\circ}$ 3688/41), onde em seu art. 42 descreve a contravenção de perturbação do trabalho ou sossego alheios como:

Art. 42. Perturbar alguém, o trabalho ou o sossego alheios:

I - com gritaria ou algazarra;

II - exercendo profissão incômoda ou ruidosa, em desacordo com as prescrições legais;

III - abusando de instrumentos sonoros ou sinais acústicos;

IV - provocando ou não procurando impedir barulho produzido por animal de que tem guarda:

Pena - prisão simples, de 15 (quinze) dias a 3 (três) meses, ou multa. 


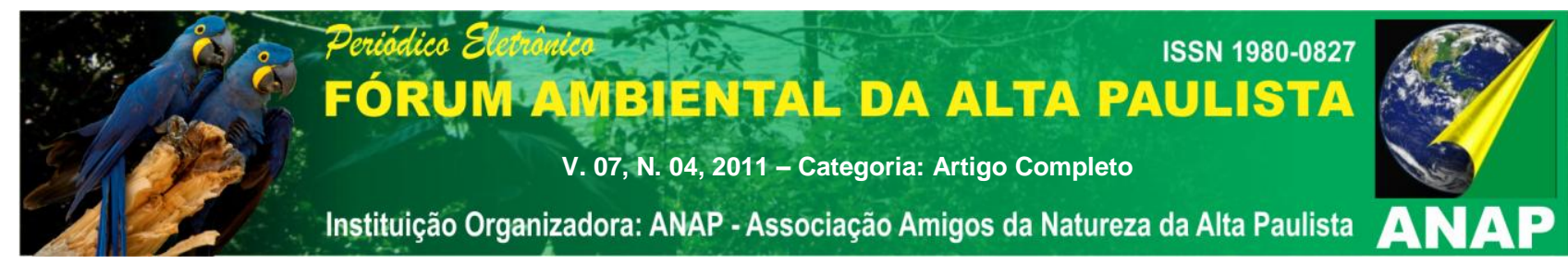

O incômodo causado ao trabalho ou ao sossego de alguém não é punido em níveis mínimos ou de forma não intencional assim como nos descreve SZNICK (2003)

Importante ressaltar que aludida contravenção não penaliza todo e qualquer ruído pequeno, de leve rumor, que em indivíduos mais irritadiços podem causar incômodos. Desse modo, excluem-se rumores usuais de uma casa, como o arrastar de móveis, as festinhas normais (de aniversário), que são manifestações expansivas da alegria e nas quais não se nota a intenção de querer molestar ou ofender.

É possível o questionamento a respeito de a lei de crimes ambientais, em seu art. 54, revogar o tipo penal contravencional. Porém esta indagação é de resposta negativa, pois ao se analisar o art. 42 da leis de contravenções penais, percebe-se que na contravenção descrita um menor potencial ofensivo, tal qual perturbar o trabalho ou sossego de alguém.

Já ao analisarmos o tipo penal descrito na lei de crimes ambientais, é percebido que o bem jurídico tutelado possui caráter de difusibilidade, ou seja, não identificará uma vítima determinada e sim a coletividade. Além disso, essa poluição deverá resultar ou, ao menos, ter potencialidade de resultar em danos à saúde humana.

Ainda a respeito da Poluição Sonora assim descrita na lei de crimes ambiental, ressalta FIORILLO (2011):

Urge salientar ainda que o delito em tela é um crime de perigo concreto, 0 que significa dizer que o legislador não presumiu o perigo, exigindo do acusador a sua prova. A adoção de crimes de perigo encontra-se em perfeita consonância com o direito ambiental, privilegiando-se o princípio da prevenção. Dessa forma, a conduta criminosa já estará caracterizada com a potencialidade de dano, sendo desnecessária para a tipificação a realização do resultado naturalístico danoso.

\section{CONCLUSÃO}


A grande proporção atingida pela degradação ambiental vem criando uma conscientização global no sentido de preservar o meio ambiente.

A poluição sonora vem sendo objeto de pesquisa e está entre umas das três prioridades ecológicas para a próxima década, visto sua incidência no cotidiano e o seu potencial degradador.

Portanto, a sociedade deve valer-se dos instrumentos jurídicos em seu favor, em busca de uma forma de melhorar sua qualidade de vida, seja ela preventiva ou repressiva, pois segundo o nosso Texto Maior, todos têm direito a um meio ambiente sadio e equilibrado, bem como o dever do Poder Público e da coletividade de defendê-lo e preservá-lo.

\section{REFERÊNCIAS}

FIORILLO, Celso Antônio Pacheco. Curso de direito ambiental brasileiro. 12 ed. São Paulo: Saraiva, 2011.

KWITKO, A. Tópicos em audiometria industrial em conservação da audição: revisão crítica da NR-7 e proposta para nova legislação. 1 ed. São Paulo: 1993.

SILVA, Anderson Furlan Freire da; FRACALOSSI, William. Direito Ambiental. 1 ed. Rio de Janeiro, Forense: 2010

SOUZA, Fernando Pimentel. A poluição sonora ataca traiçoeiramente o corpo. Disponível em: http://www.icb.ugmg.br

http://smmaspbh.vilabol.uol.com.br/10151.htm. Acesso em 08/09/2011.

http://www.direitonet.com.br/artigos/exibir/1869/Poluicao-sonora. Acesso em $12 / 09 / 2011$

http://monografias.brasilescola.com/geografia/poluicao-sonora.htm Acesso em 05/09/2011 


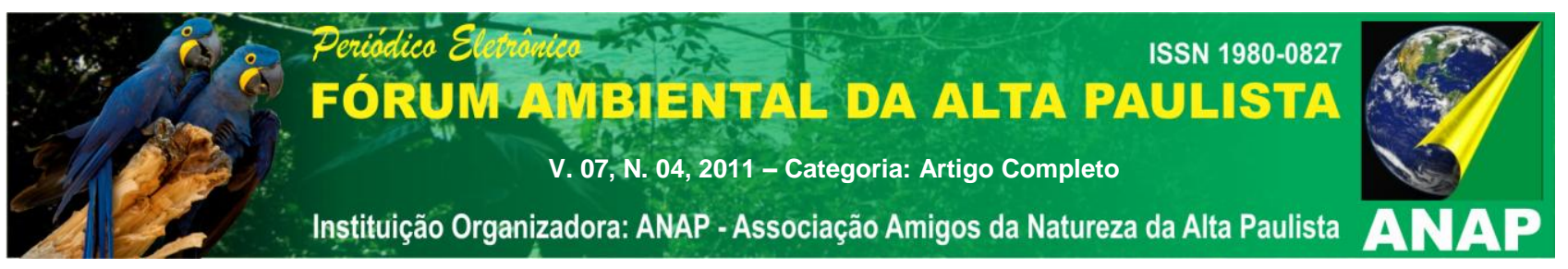

http://www.cjf.jus.br/revista/numero3/artigo05.htm Acesso em 03/09/2011.

http://www.jusbrasil.com.br/legislacao/anotada/2362114/art-30-da-constituicaofederal-de-88. Acesso em 11/09/2011

http://www.planalto.gov.br/ccivil_03/constituicao/constitui\%C3\%A7ao.htm Acesso em 02/09/2011.

http://jus.com.br/revista/texto/5261/poluicao-sonora-como-crime-ambiental/2. Acesso em 15/09/2011. 